\title{
HISTOLOGICAL AND ULTRASTRUCTURAL EVALUATION OF THE EFFECT OF PLATELET RICH PLASMA (PRP) ON WOUND HEALING IN THE TONGUE OF NORMAL AND STREPTOZOTOCIN-INDUCED DIABETIC ALBINO RATS
}

Mary Moheb Ramzy*, Tarik Ahmed Essawy**, Ali Shamaa* and Saher Sayed Ali Mohammed*

\begin{abstract}
Background: Diabetes Mellitus causes many systemic and oral complications including impaired wound healing. Recently, platelet-rich plasma (PRP) treatment to utilize a patient's own platelets and growth factors to improve healing at the site of injury has been used extensively.

Objective: Evaluation of the effect of PRP on tongue wound healing in normal and Streptozotocin-induced diabetic albino rats by H\&E and Masson's trichrome histological stains and by TEM ultrastructural examination.

Methodology: A total number of 108 adult male albino rats with average weight $200 \mathrm{gm}$, were used in the experiment. The rats were classified into two main groups: non-diabetic and diabetic groups. Each group was further divided into three subgroups: non-treated wound, PRP-treatment before wound, and PRP-treatment after wound. Tongue specimens were dissected on postoperative days 3,7 , and 10 . The specimens were examined histologically by H\&E and MT, and ultrastructurally by TEM.

Results: The most rapid wound healing was revealed in the non-diabetic and diabetic subgroups treated with PRP before the wound, which occurred very early at the $3^{\text {rd }}$ day postoperative. While complete wound healing was revealed at the $7^{\text {th }}$ day postoperative in both the non-diabetic and diabetic subgroups treated with PRP after the wound, which was like the non-diabetic control subgroup. Whilst, the diabetic non-treated subgroup was the last to show wound healing which took place at the $10^{\text {th }}$ day postoperative.
\end{abstract}

Conclusion: PRP could be applied before or after wounding occurs, to prevent impaired wound healing and to enhance wound healing in diabetic and non-diabetic oral mucosal wounds.

KEY WORDS: Platelet rich plasma, diabetic wound, tongue, Masson's trichrome, TEM

\footnotetext{
* Oral Biology Department, Faculty of Dentistry, Minia University.

** Oral Biology Department, Faculty of Oral and Dental Medicine, Cairo University.
} 


\section{INTRODUCTION}

Wound healing is a complex and dynamic process that is regulated by interactions between a large number of cell types, extracellular matrix proteins and mediators such as cytokines and growth factors (Bennett \& Schultz, 1993) ${ }^{[4]}$. Many types of cells are involved in each phase of wound healing including immune cells, endothelial cells, keratinocytes, and fibroblasts which undergo marked changes in gene expression and phenotype (Gurtner, Werner, Barrandon, \& Longaker, 2008; Singer \& Clark, 1999) ${ }^{[14,34]}$.

Diabetes Mellitus (DM) is associated with several tissue changes which result in many systemic and oral complications. Various inflammatory diseases and soft tissue pathologies in oral cavities occur in patients with DM. The prevalence of DM, and this spectrum of oral pathology, suggests that DM is the most important systemic disease encountered in patients presenting to the dental office (AbdElmotelb, 2018; Lamster, 2014; Rabo \& Mohamed, 2018) ${ }^{[2,20,31]}$.

Blood is an important source of essential therapeutic products that comprise both cellular and protein products and that cannot be obtained from other sources. The bioactive molecules, which are involved in the wound healing process, are contained in the $\alpha$-granules of circulating platelets (Blair \& Flaumenhaft, 2009) ${ }^{[5]}$.

Recently, the concept of platelet-rich plasma (PRP) treatment to utilize a patient's own platelets and growth factors to improve healing at the site of injury has been used extensively in dentistry, oral/ maxillofacial surgery, orthopedics, sports medicine, dermatology, cosmetic surgery; and plastic and reconstructive surgery (A Hamid, Yusof, \& Ali, 2014; Chicharro-Alcántara et al., 2018; Dhillon, Schwarz, \& Maloney, 2012; Kramer \& Keaney, 2018; Middleton, Barro, Muller, Terada, \& Fu, 2012; O'Connell, Wragg, \& Wilson, 2019; Tian et al., 2019) ${ }^{[1,7,10,19,25,28,36]}$.
Moreover, various research studies have been designed to study the effect of PRP on cutaneous wounds whether in mice (Law, Chowdhury, Saim, \& Idrus, 2017) ${ }^{[21]}$, or rats (Mehmet Esat Duymus et al., 2016; Venter, Marques, Santos, \& MonteAlto-Costa, 2016) ${ }^{[24,37]}$, or rabbits (Chicharro et al., 2018; Molina-Miñano, López-Jornet, CamachoAlonso, \& Vicente-Ortega, 2009; Ostvar et al., 2015) ${ }^{[8,26,29]}$, or dogs (Jee et al., 2016) ${ }^{[18]}$, or horses (Maciel et al., 2012) ${ }^{[23]}$, or clinically in human patients (Tian et al., 2019) ${ }^{[36]}$.

In mammals, the oral mucosa can be broadly divided into three subtypes: masticatory (hard palate and gingiva), lining (buccal mucosa, ventral surface of the tongue, soft palate, intra-oral surfaces of the lips and alveolar mucosa) and specialized (dorsal surface of the tongue) (Winning \& Townsend, 2000) ${ }^{[39]}$.

Historically, transmission electron microscopes (TEMs) were developed because of the limited image resolution in light microscopes, which is imposed by the wavelength of visible light. TEMs are capable of imaging at a significantly higher resolution than light microscopes (Choudhary \& Choudhary, 2018; Williams \& Carter, 2009) ${ }^{[9,38] .}$

To our knowledge, there were very limited histological and ultrastructural studies reporting the effect of PRP application on wounds in diabetic rat tongue, therefore this was the concern of the present study. Moreover, whether PRP application could be used as a prophylactic rather than a therapeutic especially in diabetic wounds; is also an unanswered issue adopted in the current study.

\section{MATERIAL AND METHODS}

\section{Animals}

A total number of 108 adult male albino rats (average weight $=200 \mathrm{gm}$ ) were used in this experiment. The animals were housed in cages at the Faculty of Medicine, Minia University in Egypt 
under the optimal experimental conditions. Animals were fed on standard chow pellets and supplied water ad-libitum. Housing and environmental conditions were assured to meet the basic needs of the animal subjects. Ethical guidelines for use of animals in scientific research were carefully followed throughout this experiment (Tandon et al., 2000) ${ }^{[35]}$.

\section{Experimental design:}

The animals were classified into two main groups:

The Non- diabetic group (Group N): comprised 54 animals. They were injected with citrate buffer. These animals were subdivided into 3 subgroups (18 animals each):

Subgroup N1: was the control group. The rats received an incisional wound in their tongues. These rats were in turn divided into three subgroups (six animals each). In the first subgroup, the wounded tongue was injected with saline on postoperative day 1 , and then the rats were sacrificed on the $3^{\text {rd }}$ day postoperative. In the second subgroup, the wounded tongue was injected with saline on postoperative days 1 and 3 , and then the rats were sacrificed on the $7^{\text {th }}$ day postoperative. In the third subgroup, the wounded tongue was injected with saline on postoperative days 1,3 and 7 , and then the rats were sacrificed on the $10^{\text {th }}$ day postoperative.

Subgroup N2: $0.1 \mathrm{ml}$ of freshly prepared PRP solution was injected in the rats' tongues before the incisional wound by about 10 minutes. These rats were in turn divided into three subgroups (six animals each). In the first subgroup, the wounded tongue was injected with saline on postoperative day 1 , and then the rats were sacrificed on the $3^{\text {rd }}$ day postoperative. In the second subgroup, the wounded tongue was injected with saline on postoperative days 1 and 3 , and then the rats were sacrificed on the $\mathbf{7}^{\text {th }}$ day postoperative. In the third subgroup, the wounded tongue was injected with saline on postoperative days 1,3 and 7 , and then the rats were sacrificed on the $10^{\text {th }}$ day postoperative.

Subgroup N3: The rats' tongues were injected with $0.1 \mathrm{ml}$ of freshly prepared PRP solution after the incisional wound by about 10 minutes. These rats were in turn divided into three subgroups (six animals each). In the first subgroup, PRP was injected into the wounded tongue on postoperative days 0 and 1 , and then the rats were sacrificed on the $3^{\text {rd }}$ day postoperative. In the second subgroup, PRP was injected into the wounded tongue on postoperative days 0,1 and 3 , and then the rats were sacrificed on the $\mathbf{7}^{\text {th }}$ day postoperative. In the third subgroup, PRP was injected into the wounded tongue on postoperative days $0,1,3$ and 7 , and then the rats were sacrificed on the $\mathbf{1 0}^{\text {th }}$ day postoperative.

The Diabetic group (Group D): comprised 54 animals. Diabetes was induced in these rats by a single intraperitoneal injection of $45 \mathrm{mg} / \mathrm{kg}$ body weight of streptozotocin (STZ) dissolved in 0.1 $\mathrm{M}$ citrate buffer ( $\mathrm{pH}$ 4.5). This group in turn was subdivided into three subgroups (18 animals each):

Subgroup D1: The rats received an incisional wound in their tongues after induction of diabetes. These rats were further divided into three subgroups (six animals each) and the wounded tongue was injected with saline like the three subgroups of the control subgroup N1.

Subgroup D2: The diabetic rats were treated with PRP before the incisional wound. These rats were further divided into three subgroups (six animals each) and the wounded tongue was injected with saline like the three subgroups of subgroup N2.

Subgroup D3: The diabetic rats were treated with PRP after the incisional wound. These rats were further divided into three subgroups (six animals each). PRP was injected into the wounded tongue on postoperative days like the three subgroups of subgroup N3. 
Diabetes: After 48 hours, blood samples were collected via the tail vein from the rats in group D that received STZ injection and the glucose level was estimated using Glucometer. Rats with persistent blood glucose levels $\geq 250 \mathrm{mg} / \mathrm{dL}$ until wounding were confirmed diabetic and used for the experiment.

Wounding: General anesthesia was induced in all the rats using intramuscular injection of ketamine at a dose of $20 \mathrm{mg} / \mathrm{kg}$. Then the incisional wound was made on the lateral border of the rat tongue $1 \mathrm{~cm}$ length and $0.5 \mathrm{~cm}$ depth by using a small surgical scalpel.

PRP Preparation: Under general anesthesia, whole blood was drawn from each rat that was going to be treated with PRP, from the retro-orbital plexus by using capillary tube. Centrifugation of the blood was done at $6000 \mathrm{rpm}$ (revolutions per minute) for 3 minutes at room temperature. This resulted in separation of blood into three fractions which are red blood cells (bottom layer), platelet-poor plasma (PPP) (top layer), and PRP (middle layer, including white blood cells and platelets (buffy coat)). PRP was then aspirated with a pipette and placed in a sterile syringe to be ready for injection (Dhurat \& Sukesh, 2014) ${ }^{[11]}$.

\section{HISTOLOGICAL PROCEDURES:}

In the end of the experiment, the animals were humanely sacrificed under general anesthesia by diethyl ether $\left[\left(\mathrm{C}_{2} \mathrm{H}_{5}\right)_{2} \mathrm{O}\right]$ inhalation on postoperative days 3,7 , and 10 . Specimens from the normal and diabetic rats' tongues were carefully dissected perpendicular to the wound sites and to the midline of their tongues. Half of these specimens were fixed in $10 \%$ neutral buffered formalin for histological analysis. The other half of the specimens were fixed in glutaraldehyde for $24-48$ hours at $4^{\circ} \mathrm{C}$ for transmission electron microscopic analysis.

Light Microscopic Preparation: The formalinfixed tongue samples were washed under running tap water, then dehydrated through ascending grades of ethyl alcohol, cleared in xylol, and embedded in paraffin wax. Sections of $5 \mu$ thick were cut, mounted on clean glass slides, and stained with routine H\&E stain to verify histological details and Masson's trichrome (MT) to assess the degree of collagen deposition. All these methods were adopted according to (Drury \& Wallington, 1980) ${ }^{[12]}$.

\section{Microscopic examination of the histological} slides: The prepared slides (H\&E and MT) were examined and photographed by using light microscope (LEICA, model DM LB100T, Germany) connected to digital camera (LEICA Microsystem, Type DFC295, Germany) in Histopathology Unit in Faculty of Dentistry, Minia University.

TEM Processing: Immediately after dissecting the animals for $24-48$ hours, four blocks ( $1 \times 2 \mathrm{~mm})$ were taken from each sample and fixed in 5\% cold glutaraldehyde. The specimens were then washed in cacodylate buffer ( $\mathrm{pH} 7.2$ ) 3-4 times for 20 minutes every time and post fixed in $1 \%$ osmium tetroxide $\left(\mathrm{O}_{4} \mathrm{~S}_{4}\right)$ for 2 hours, after that washed in the same buffer four times. Dehydration by ascending grades of alcohol (30 - 50 - $70-90$ and 100\% 2 hours) of each was done. Specimens were then embedded in epon - araldite mixture (Bozzola \& Russell, 1999) [6]. From the embedded blocks semithin sections by LKB ultramicrotome in thickness of $0.5-1$ micron were prepared for orientation of the tissue. These semithin sections were photographed by SC30 Olympus camera. Ultrathin sections in thickness of $500-700 \mathrm{~A}$ were prepared using Leica AG ultramicrotome and contrasted in uranyl acetate and lead citrate. Ultrathin sections were examined by JEM 100 CXII electron microscope at $80 \mathrm{KV}$ and photographed by CCD digital camera Model XR- 41 at the Electron Microscopy Unit of Assiut University. 


\section{RESULTS}

\section{Haematoxylin and Eosin Stain Results}

\section{First: The Non- diabetic group (Group N)}

Subgroup N1: On the $3^{\text {rd }}$ day postoperative, the granulation tissue composed of fibroblasts and newly formed blood vessels appeared filling the wound gap which was surrounded with non-keratinized epithelium. On the $\mathbf{7}^{\text {th }}$ day postoperative, the wound gap appeared to be healed with thin keratinized stratified squamous epithelium. On the $\mathbf{1 0}^{\text {th }}$ day postoperative, the basal cells of the keratinized stratified squamous epithelium appeared deeply stained and lamina propria showed thin collagenous C.T. fibers.

Subgroup N2: On the $\mathbf{3}^{\text {rd }}$ day postoperative, completely healed lightly stained keratinized stratified squamous epithelium was displayed. Thin layer of lamina propria with absence of granulation tissue was shown. Newly formed blood vessels were clearly seen. On the $7^{\text {th }}$ day postoperative, completely healed deeply stained keratinized stratified squamous epithelium with well differentiated keratinocytes was revealed. Thin layer of lamina propria appeared with newly formed blood vessels. On the 10th day postoperative, fully mature keratinized stratified squamous epithelium with rete pegs was obviously seen.

Subgroup N3: On the $3^{\text {rd }}$ day postoperative, the wound area started to heal by formation of thick layer of edematous stratified squamous epithelium with no rete pegs. Granulation tissue with inflammatory cell infiltrate and newly formed blood vessels was observed. On the $\mathbf{7}^{\text {th }}$ day postoperative, completely healed thick layer of keratinized stratified squamous epithelium was displayed. On the 10th day postoperative, complete healing with fully mature thin layer of keratinized stratified squamous epithelium occurred. Thin layer of lamina propria and well-organized muscle fibers were observed.

\section{Second: The Diabetic group (Group D)}

Subgroup D1: On the $3^{\text {rd }}$ day postoperative, granulation tissue was clearly noticed filling the wound gap with inflammatory cell infiltrate. Wound margins appeared to be formed of keratinized stratified squamous epithelium. On the $7^{\text {th }}$ day postoperative, partial healing in the wound epithelial covering with lightly stained keratinized stratified squamous epithelium was noticed with presence of small wound gap. On the 10th day postoperative, the epithelial covering displayed regular rete pegs with deeply stained basal cells. Lamina propria showed collagenous C.T. fibers and blood vessels.

Subgroup D2: On the $3^{\text {rd }}$ day postoperative, the wound appeared to be completely healed with thick keratinized stratified squamous epithelium. Lamina propria was shown to be composed of fibroblasts, inflammatory cell infiltrate and newly formed blood vessels. On the $7^{\text {th }}$ day postoperative, the wound was observed to be completely healed with keratinized stratified squamous epithelium with regular rete pegs. On the 10th day postoperative, fully mature keratinized stratified squamous epithelium with regular rete pegs projecting into the underlying thin lamina propria was apparent.

Subgroup D3: On the $3^{\text {rd }}$ day postoperative, the wound gap was noticed to be surrounded by edematous keratinized stratified squamous epithelial margins. Granulation tissue appeared to be composed of inflammatory cell infiltrate, fibroblasts, and newly formed blood vessels. On the $7^{\text {th }}$ day postoperative, the wound area was found to be completely healed by thin, lightly stained keratinized stratified squamous epithelium with regular rete pegs. Lamina propria showed thick collagen bundles. On the 10th day postoperative, complete healing of wound area by thin layer of fully mature keratinized stratified squamous epithelium was obvious. 


\section{Masson's Trichrome Stain Results}

\section{First: The Non- diabetic group (Group N):}

Subgroup N1: On the $3^{\text {rd }}$ day postoperative, moderately stained, and thick collagen fibers which were randomly distributed, were displayed. Obvious newly formed blood vessels were also seen. There was thick granulation tissue with inflammatory cells infiltration related to the wound area (Figure 1). On the $7^{\text {th }}$ day postoperative, thick, and intensively stained collagen fibers arranged parallel to the epithelial surface were shown. Very dilated and congested blood vessels were apparent. On the $\mathbf{1 0}^{\text {th }}$ day postoperative, thick layer of intensively stained collagen fibers were seen parallel to the epithelial surface.

Subgroup N2: On the $\mathbf{3}^{\text {rd }}$ day postoperative, superficial layer of collagen fibers was thin, intensely stained, and parallel to the epithelial surface. Deep layers of collagen fibers were delicate, intensely stained, and perpendicular to the epithelial surface extending in between the muscle bundles (Figure 1). On the $7^{\text {th }}$ day postoperative, thin, moderately stained superficial layer of collagen fibers which appeared parallel to the epithelial surface were displayed. Thin delicate collagen fibers between muscle bundles were seen perpendicular to the epithelium. Newly formed blood vessels (angiogenesis) were apparent. On the 10th day postoperative, thick mildly stained collagen fibers were displayed in the lamina propria. Thin delicate collagen fibers between muscle fibers bundles were shown perpendicular to the epithelium.

Subgroup N3: On the $3^{\text {rd }}$ day postoperative, the collagen fibers were shown to be thin, moderately stained, and randomly distributed. Thick layer of granulation tissue appeared with inflammatory cells infiltrate in the wound area. Newly formed blood vessels were apparent. On the $\mathbf{7}^{\text {th }}$ day postoperative, thin moderately stained collagen fibers arranged parallel to the epithelial surface were displayed.
Presence of newly formed blood vessels was obvious. On the 10th day postoperative, the collagen fibers appeared thick moderately stained and arranged perpendicular to the epithelial surface. Newly formed blood vessels were shown in the lamina propria (Figure 1).

\section{Second: The Diabetic group (Group D):}

Subgroup D1: On the $\mathbf{3}^{\text {rd }}$ day postoperative, the collagen fibers were shown to be thin, moderately stained and arranged in a haphazard manner. Thick granulation tissue was displayed filling the wound gap and containing extensive inflammatory cells infiltrate (Figure 1). While on the $7^{\text {th }}$ day postoperative, the collagen fibers appeared thick and intensely stained. On the 10th day postoperative, the collagen fibers were thick, and moderately stained. Superficial fibers were parallel to the epithelial surface while deep fibers were perpendicular extending in between the muscle bundles.

Subgroup D2: On the $\mathbf{3}^{\text {rd }}$ day postoperative, the collagen fibers were observed to be thin, deeply stained and randomly distributed. Newly formed blood vessels were noticed. On the $7^{\text {th }}$ day postoperative, displayed thick deeply stained collagen fibers arranged parallel to the epithelial surface. Delicate fibers were shown to be perpendicular to the epithelial surface and surrounding the muscle fibers bundles (Figure 1). On the 10th day postoperative, the collagen fibers were moderately stained, and thick. Superficial layer of fibers appeared parallel to the epithelial surface, while the deep layer appeared perpendicular and surrounding the muscle fibers bundles.

Subgroup D3: On the $\mathbf{3}^{\text {rd }}$ day postoperative, the collagen fibers were thin moderately stained and randomly distributed. Newly formed blood vessels were seen. Thick granulation tissue with inflammatory cells infiltration related to the wound area was clearly seen. On the $\mathbf{7}^{\text {th }}$ day postoperative, moderately stained thick collagen fibers which 
appeared perpendicular to the epithelial surface were displayed. Newly formed blood vessels were obviously seen in the lamina propria. On the 10th day postoperative, the collagen fibers were moderately stained and thick with the superficial layer distributed parallel to the epithelial surface. Deep layers of fibers were found to be perpendicular to the epithelial surface and surrounding the muscle fibers bundles. Newly formed blood vessels were noticed in the lamina propria (Figure 1).

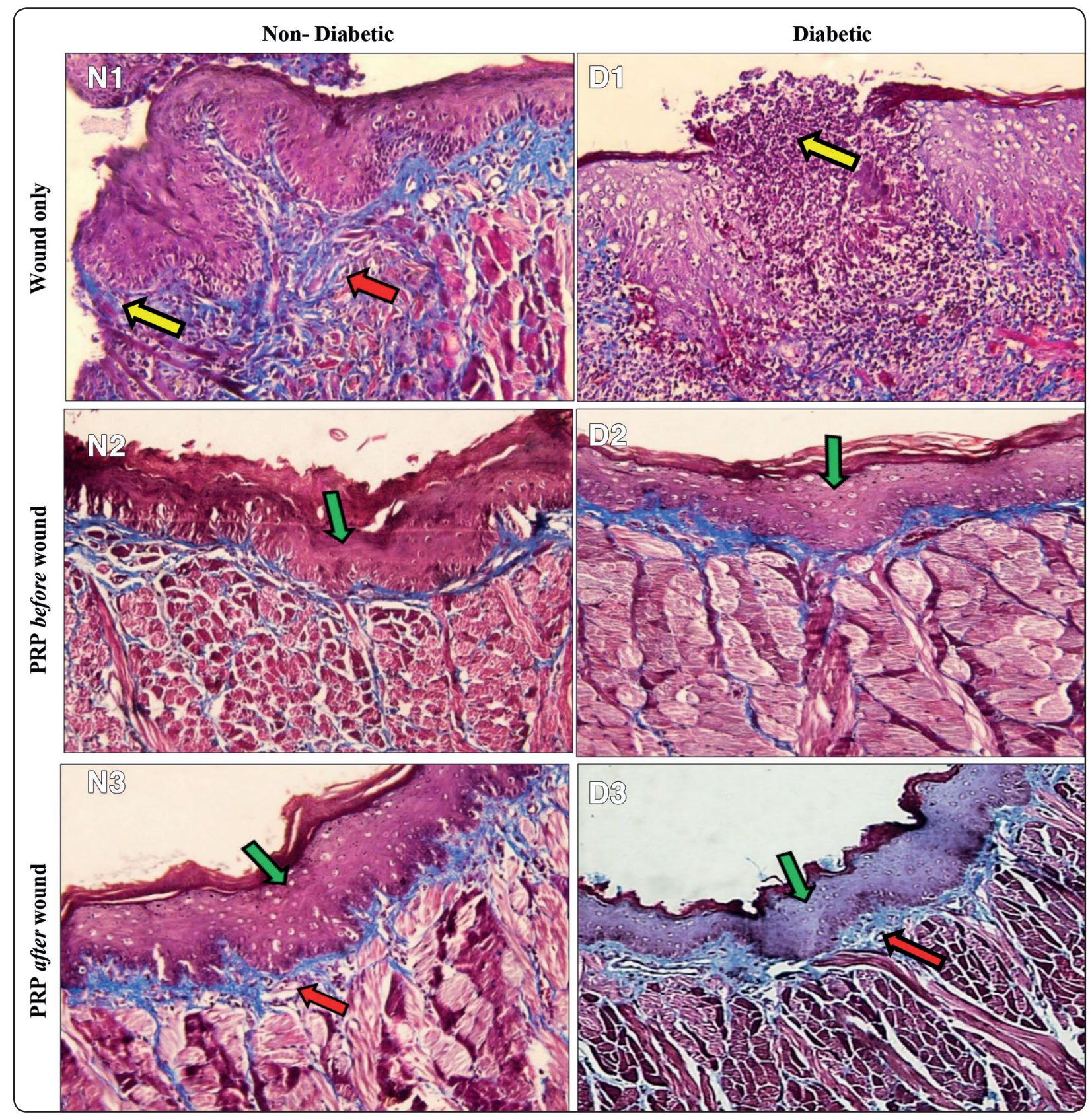

Fig. (1) Photomicrographs of the wound area of the tongue of Non-diabetic subgroups (N1 in the 3rd day, N2 in the 3rd day, and N3 in the 10th day postoperative), and Diabetic subgroups (D1 in the 3rd day, D2 in the 7th day, and D3 in the 10th day postoperative), showing blue stained collagen fibers with ranging thickness and arrangement; granulation tissue filling wound gap (yellow arrow); newly formed blood vessels (red arrow); and healed epithelium (green arrow). (MT X200) 


\section{Transmission Electron Microscope Results}

\section{First: The Non- diabetic group (Group N):}

Subgroup N1: On the $3^{\text {rd }}$ day postoperative, ultra-thin sections under TEM, showed polyhedral cells in the wound margin having indented vesicular nucleus which contained a large nucleolus and large amount of euchromatin. In addition, the presence of desmosomes in between the cells with small intercellular spaces was observed. On the $7^{\text {th }}$ day postoperative, the basal cell layer in the healing area showed indentation of the nucleus and vacuolation of the cell with condensation of the nuclear chromatin. The cytoplasm of the cells was rich in free ribosomes (Figure 2). On the 10th day postoperative, the basal cell layer in the wound healing area revealed active, proliferative, electron dens basal cells, rich in free ribosomes, with presence of some bi-nucleated cells, as well as dilatation of the intercellular spaces.

Subgroup N2: On the $\mathbf{3}^{\text {rd }}$ day postoperative,
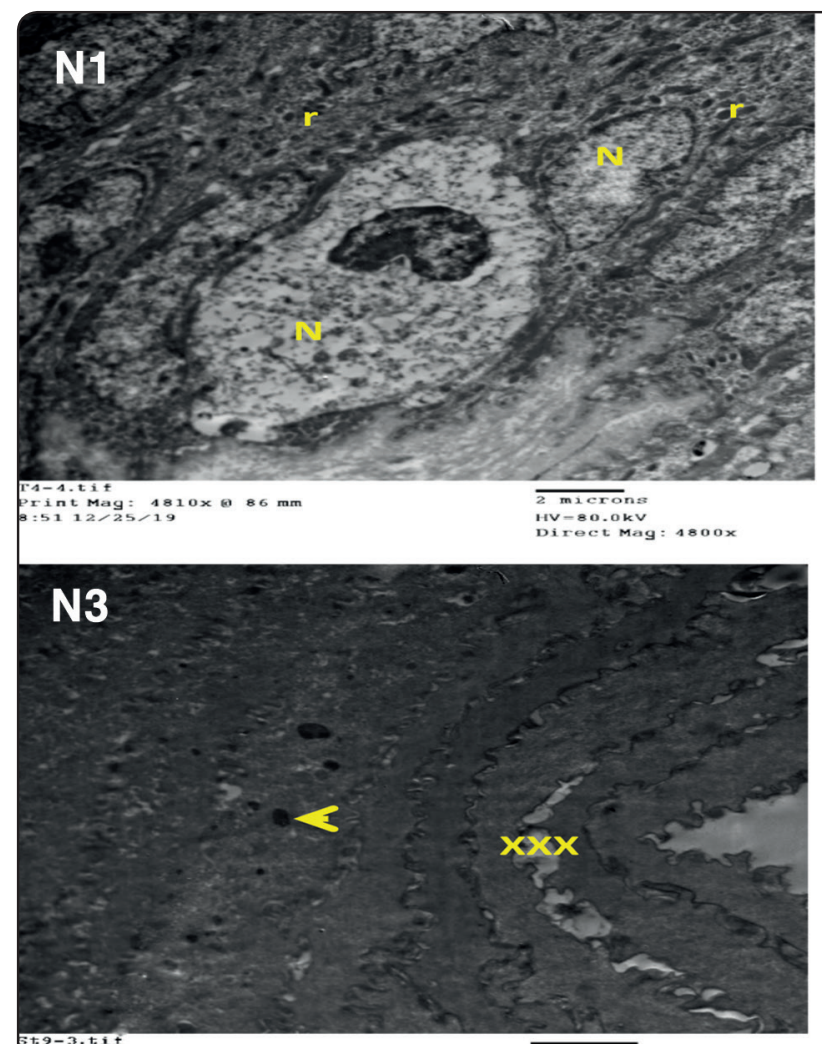

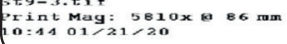

2 microns
HV-80.0kv ultra-thin sections under TEM, displayed the basal cell layer as elongated or cuboidal cells having large vesicular indented nucleus, some of which were in state of mitosis, and presence of wide intercellular spaces with desmosomes (Figure 2). On the $\mathbf{7}^{\text {th }}$ day postoperative, the surface epithelial cells were found to contain electron dens spherical hyaline granules in their cytoplasm which were variable in size, and their nucleus was light electron dens and indented. On the 10th day postoperative, the ultrathin section was like subgroup N1.

Subgroup N3: On the $3^{\text {rd }}$ day postoperative, ultra-thin sections showed the superficial epithelial layers consisting of flattened lamellate epithelial cells having indented nucleus and vacuolated cytoplasm and there was dilatation of the intercellular spaces. On the $7^{\text {th }}$ day postoperative, the surface epithelial cells were observed to be arranged in lamellar manner and their nucleus contained a nucleolus with presence of peri-nuclear space and their cytoplasm

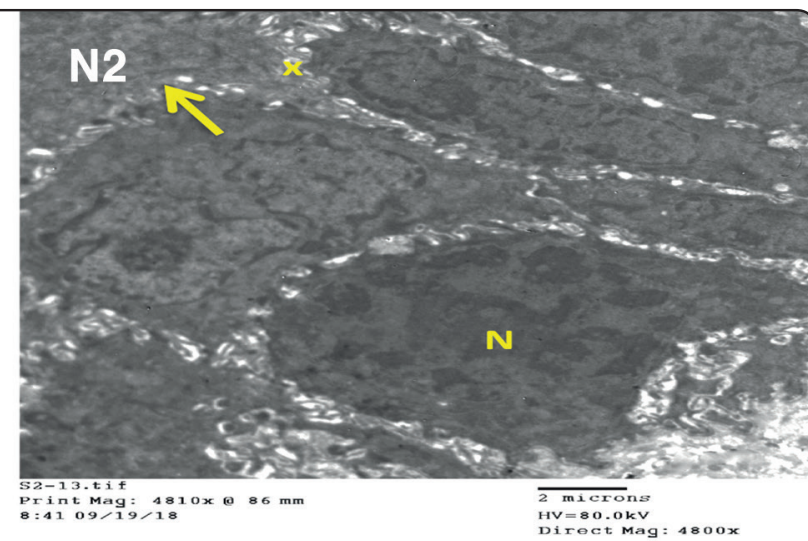

Fig. (2) T.E. micrographs of the wound area of Non-diabetic subgroups ( $\mathrm{N} 1$ in the 7th day, $\mathrm{N} 2$ in the 3rd day and $\mathrm{N} 3$ in the 7 th day postoperative), showing indented vesicular nucleus (N), desmosomes (arrow), intercellular spaces $(\mathrm{X})$, free ribosomes (r), electron dens hyaline granules (arrowhead), and lamellate layers of keratin $(\mathrm{XXX})$. 
contained small electron dens hyaline granules. The presence of vacuoles or empty spaces in between the lamellate layers of keratin was observed (Figure 2). On the 10th day postoperative, the ultrathin section was like subgroup N1.

\section{Second: The Diabetic group (Group D):}

Subgroup D1: On the $3^{\text {rd }}$ day postoperative, ultra-thin sections revealed separation of the lamellar arrangement of the surface epithelium with edema, and presence of vacuolated cells having condensed electron dens nucleus was noticed. On the $7^{\text {th }}$ day postoperative, the surface epithelial cell layers appeared flattened having vesicular nucleus and the intercellular spaces were dilated and contained vacuoles (Figure 3). On the 10th day postoperative, the ultrathin section was like subgroup N1.

Subgroup D2: On the $3^{\text {rd }}$ day postoperative, two or three cell layers having large vesicular nucleus with tendency to form the flattened surface cell layer
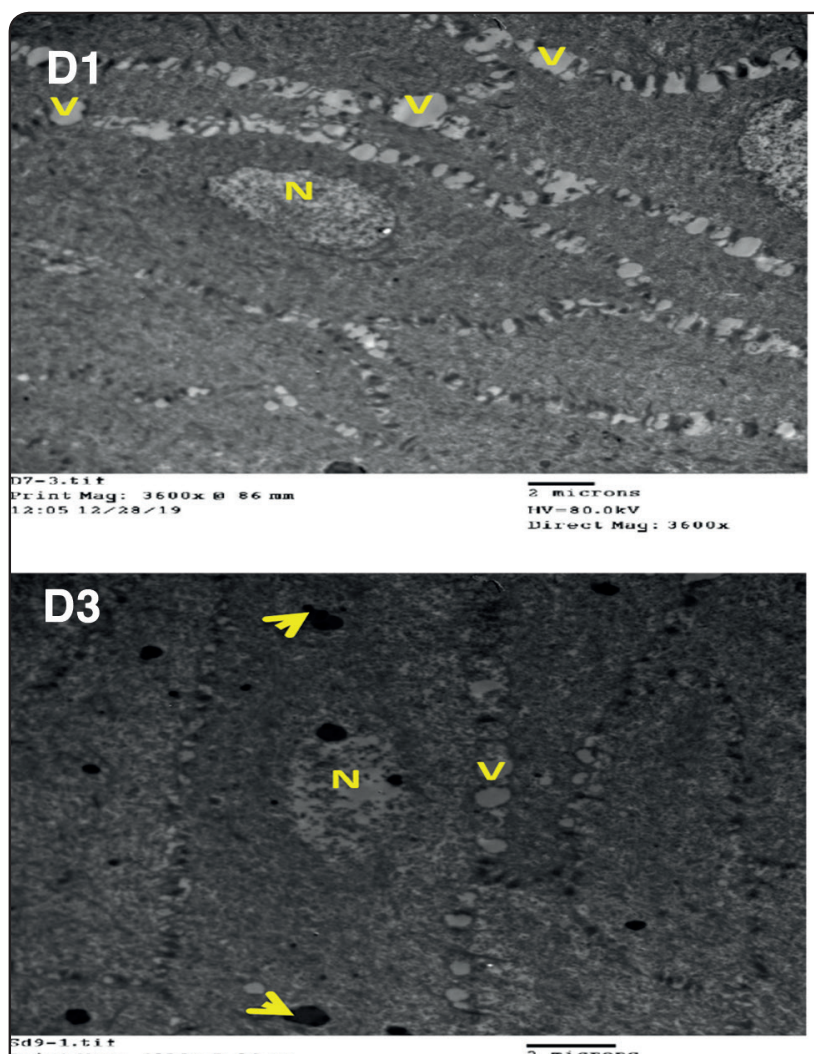

in the edges were observed under TEM examination (Figure 3). On the $7^{\text {th }}$ day postoperative, the basal cells were displayed with large indented vesicular nucleus containing prominent nucleolus. Moreover, edema was observed in the sub-epithelium extending in between the basal cells. On the 10th day postoperative, the ultrathin section was like subgroup N1.

Subgroup D3: On the $3^{\text {rd }}$ day postoperative, ultra-thin sections under TEM, displayed marked degenerative changes of vacuolar type in the epithelial covering with presence of fat globules. The nucleus of the cells was granular and light electron dens. On the $\mathbf{7}^{\text {th }}$ day postoperative, the nucleus of the surface epithelial cells was light electron dens, their cytoplasm contained electron dens hyaline granules and the intercellular spaces were dilated and contained vacuoles (Figure 3). On the $\mathbf{1 0}^{\text {th }}$ day postoperative, the ultrathin section was like subgroup N1.

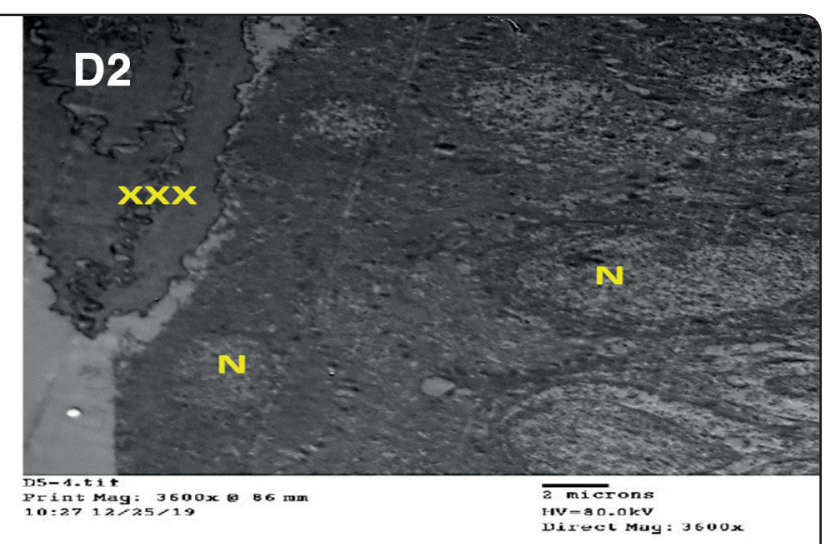

Fig. (3) T.E. micrographs of the wound area of Diabetic subgroups (D1 in the 7th day, D2 in the 3rd day and D3 in the 7th day postoperative), showing indented vesicular nucleus $(\mathrm{N})$, electron dens hyaline granules (arrowhead), vacuoles (V), and lamellate layers of keratin $(\mathrm{XXX})$. 


\section{DISCUSSION}

Although several studies were performed on the dorsal surface of the tongue (Gazaerly, Elbardisey, Eltokhy, \& Teaamab, 2013; López-Jornet, Camacho-Alonso, Molina-Miñano, \& VicenteOrtega, 2009) ${ }^{[13,22]}$, it wasn't preferred in our study because it is specialized mucosa containing papillae and taste buds differing from the rest of oral epithelial tissues. Therefore, in the current study, the lateral surface of the tongue which represents lining mucosa, was chosen as it would be subjected to less friction from food particles than the dorsal surface and so additional insult probably causing impaired wound healing was avoided.

In our study, we evaluated both epithelium and C.T. during wound healing by routine $H \& E$ histological stain and ultra-structural examination by TEM. Masson's trichrome (MT) stain was concerned with the evaluation of the C.T. component of wound healing where collagen was well identified by the concentration of the blue stain.

New C.T. begins to form approximately $2-4$ days after wounding, and it is called granulation tissue. Granulation tissue derives its name from one of its chief components, sprouting capillaries that tend to protrude from the surface of a healing wound producing minute red granules. Cells and proliferating capillaries are the two major components of granulation tissue. The cells are chiefly fibroblasts and inflammatory cells. (Gurtner et al., 2008; Häkkinen, Larjava, \& Koivisto, 2012) ${ }^{[14,15]}$.

The granulation tissue is finally turned into a mature C.T. by a slow process called tissue remodeling that ultimately restores the C.T. structure and function. Wound remodeling stage turns the abundant and poorly organized granulation tissue extracellular matrix into a mature C.T. At the peak of granulation tissue formation the tissue is highly hypercellular with fibroblasts, macrophages, myofibroblasts and neo-vasculature (Häkkinen et al., 2012) ${ }^{[15]}$.

Remodelling starts when wound contraction has assembled the collagen fibrils into thicker bundles and aligned them perpendicularly to the wound edges. During remodeling stage, collagen crosslinking gradually increases, and there is a gradual maturation of the tissue so that the aligned collagen fiber bundles are reorganized to the typical and more resilient basket weave organization found in normal C.T (Häkkinen et al., 2012) ${ }^{[15]}$.

Normally the lamina propria is divided into two layers which are the superficial papillary layer that is associated with the epithelial ridges and the deeper reticular layer which lies between the papillary layer and the underlying structures. In the papillary layer, collagen fibers are thin and loosely arranged, and many capillary loops are present. By contrast, the reticular layer has collagen fibers arranged in thick bundles that tend to lie parallel to the surface plane (Nanci, 2018) ${ }^{[27]}$.

MT histological examination of subgroup N1 revealed thick collagen fibers which ranged from moderate to intense blue stain. The collagen fibers were randomly distributed in the $3^{\text {rd }}$ day postoperative, while in the $7^{\text {th }}$ and $10^{\text {th }}$ days postoperative, they were arranged parallel to the epithelial surface.

Trichrome histological results in the study by (Rashed, GabAllah, AbuAli, \& Shredah, 2019) [32] were shown to be to a great extent consistent with our results in the control group. On day 3 , they reported presence of thin collagen fibers at the centre of the lesion which were distributed in a haphazard manner and surrounded by numerous inflammatory cells. On day 5, 7 and 10, granulation tissue with inflammatory cell infiltrate, some blood vessels and moderately thick collagen fibers were displayed.

Moreover, MT histological results of the study by (Gazaerly et al., 2013) ${ }^{[13]}$ agreed with our results as it showed moderate staining reaction of collagen fibers with organized proliferating fibroblasts and endothelial cells with presence of numerous capillaries \& few inflammatory cells in the control group. 
MT histological examination of the lamina propria of subgroup $\mathbf{N} 2$ revealed collagen fibers ranging in thickness from thin to thick and ranging in colour intensity from mild to intense blue, in the different durations of the experiment. Superficial fibers were parallel to the epithelial surface while deep fibers were perpendicular and extending in between the muscle fibers. MT examination of the TGF- $\beta 1$ group in the study by (Gazaerly et al., 2013) ${ }^{[13]}$ supported our results as it showed intense staining reaction of collagen fibers with increased C.T. thickness, and more organized granulation tissue. TGF- $\beta 1$ is one of the growth factors present in PRP, which was injected into the dorsal surface of the rat tongue five minutes before wounding in the study by (Gazaerly et al., 2013) ${ }^{[13]}$ and so their results were comparable to subgroup N2 in our present study.

Newly formed blood vessels were clearly seen in the thin lamina propria of subgroup $\mathbf{N} 2$ at the $3^{\text {rd }}, 7^{\text {th }}$ and $10^{\text {th }}$ days postoperative by $H \& E$ and MT histological examination. H\&E histological examination of the TGF- $\beta 1$ group in the study by (Gazaerly et al., 2013) ${ }^{[13]}$ was coincidental with our results as it showed remodelling of the C.T. with increased endothelial cell proliferation and congested blood vessels with RBCs. Moreover, angiogenesis which was obvious in subgroup N2 could be attributed to the presence of VEGF, PDGF and FGF in PRP which are potent angiogenesis stimulators (Italiano et al., 2008) ${ }^{[17]}$.

In the present study, MT histological examination of subgroup N3 revealed thin to thick moderately stained collagen fibers. These fibers were randomly distributed in the $3^{\text {rd }}$ day postoperative, arranged parallel to the epithelial surface in the $7^{\text {th }}$ day postoperative and arranged perpendicular to the epithelial surface in the $10^{\text {th }}$ day postoperative. Newly formed blood vessels were shown in the lamina propria in the $7^{\text {th }}$ and $10^{\text {th }}$ days postoperative.

These findings came in line with (Rashed et al., 2019) ${ }^{[32]}$ whose trichrome histological results in the
PRP-treated group revealed a discrete deposition of thin, disorganized collagen fibers at the centre of the lesion on day 3. On day 5 and 7, there was thick granulation tissue with inflammatory cells infiltration at the surface of the wound, while the deeper layers showed less inflammation with fine interlacing collagen fibers, and numerous dilated blood vessels. On day 10, thick collagen fibers perpendicular to the surface epithelium, some inflammatory cells, and many blood vessels with extravasated red blood cells were seen.

Moreover, MT histological examination in the study by (Jee et al., 2016) ${ }^{[18]}$ revealed PRP-treated wounds showing more granulation formation and angiogenesis on day 7 , and by time more granulation formation and collagen deposition were observed than in control wounds. The dermis in PRP-treated wounds showed tightly packed collagen fibers running parallel to each other and to the epidermis. These results came in accordance to our study.

In addition, MT staining in the study by (Law et al., 2017) ${ }^{[21]}$ showed the presence of coarse collagen bundles in the reticular dermis of PRPtreated group, while the collagen bundles in the control group were sparse. This also agreed with our observations. Furthermore, MT staining in the study by (Chicharro et al., 2018) ${ }^{[8]}$ came in agreement with our results as it revealed a significant increase in blood vessel formation in PRGF-treated wounds at all studied days compared to control groups. PRGF enhanced collagen deposition at days 1, 2 and 5 compared to control groups.

H\&E histological examination done by (Ostvar et al., 2015) ${ }^{[29]}$ came in accordance to our results as it revealed that by day 7 , there were increased newly organized collagen bundles and relatively advanced epithelium at the wound junction of PRP-treated wounds as compared to non-treated wounds. Several small vessels (angiogenesis) were also apparent in the PRP treated tissues, whereas only a few vessels were present in control tissues. Moreover, by time, all PRP treated wounds contained abundant 
fibroblasts and collagen bundles, through rich neovascularization, and inflammatory responses were observed at lower frequency range than the control groups.

Accordingly, (Ostvar et al., 2015) ${ }^{[29]}$ proved that cutaneous wounds treated with PRP exhibited faster healing rates and adequate granulation tissue formation when compared to control group. In addition, they reported that PRP enhanced angiogenesis in the early stage of the repair process and subsequently promoted wound healing.

MT histological examination of subgroup D1 revealed thin to thick collagen fibers which ranged from moderate to intense blue stain in the lamina propria with presence of dilated blood vessels. Superficial fibers were parallel to the epithelial surface while deep fibers were perpendicular. Nevertheless, MT examination of the diabetic group in the study by (Gazaerly et al., 2013) ${ }^{[13]}$ showed mild staining reaction of collagen fibers, decreased C.T. thickness, and separation of muscles from underlying C.T.

MT histological examination of subgroup D2 displayed thin to thick, and moderate to deeply stained collagen fibers. These fibers were randomly distributed in the $3^{\text {rd }}$ day postoperative and arranged parallel to the epithelial surface in the $7^{\text {th }}$ day postoperative. In the $10^{\text {th }}$ day postoperative the superficial fibers were parallel to the epithelial surface, while the deep layer appeared perpendicular and surrounding the muscle fibers bundles. Newly formed blood vessels were apparent in the $3^{\text {rd }}$ day postoperative. In consistence to our observations, MT histological results of the diabetic + TGF- $\beta 1$ group in the study by (Gazaerly et al., 2013) ${ }^{[13]}$, showed moderate to intense staining reaction of collagen fibers. They also reported that the granulation tissue was apparently well-organized and rich in fibroblasts and moderate collagen fibrils. There were increased collagen bundles between muscles and increased endothelial cell proliferation.
MT histological examination of subgroup D3 revealed thin to thick moderately stained collagen fibers. These fibers were randomly distributed in the $3^{\text {rd }}$ day postoperative. In the $7^{\text {th }}$ and $10^{\text {th }}$ days postoperative, the superficial fibers were found to be distributed parallel to the epithelial surface, while the deep fibers were perpendicular to the epithelial surface and surrounding the muscle fibers bundles. Additionally, newly formed blood vessels were observed in all the durations of the experiment. In accordance with our results, (Venter et al., 2016) ${ }^{[37]}$ demonstrated that PRP-treated diabetic wounds showed more developed granulation tissue and consequently faster wound closure in PRPtreated rats than in control rats.

The transformation of the regenerated epithelium from thick to thin epithelium which was apparent at the $10^{\text {th }}$ day postoperative in all subgroups in the current study could be explained by (Law et al., 2017) ${ }^{[21]}$ who stated that epithelial maturity was indicated by the presence of thinner epidermis with single layer of thick basal keratinocytes and less cellular dermis.

In the present study, it was remarkably noticed that the healing process proceeded very rapidly in subgroup N2 which received PRP before the wound. Complete re-epithelialization of the wound area by lightly stained keratinized stratified squamous epithelium was displayed in the $3^{\text {rd }}$ day postoperative. However, in subgroup N3 which was treated with PRP after the wound, H\&E examination revealed complete re-epithelialization of the wound area at the $7^{\text {th }}$ day postoperative with thick layer of keratinized stratified squamous epithelium.

$\mathrm{H} \& \mathrm{E}$ examination of the epidermis at day 7 in the study by (Jee et al., 2016) ${ }^{[18]}$, showed that the PRP-treated wounds exhibited hypertrophied epidermis with development of stratum spinosum and stratum granulosum, abundant keratohyaline granules, and differentiated keratinocytes. Additionally, by time, all PRP-treated wounds showed decreased epithelial thickness and epithelial cells were flat- 
tened and keratinized with anuclear keratinocytes overlying the epidermis. All these findings supported our results.

In contrast to our findings, (Law et al., 2017) ${ }^{[21]}$ who studied the effect of PRP on skin wounds in mice, showed that re-epithelialization was faster in the PRP group than the control group. $H \& E$ histological analysis at day 14 in their study showed the presence of keratinized epidermal layer at the central region of the PRP-treated wounds, which was absent in the control group. While in the present study, re-epithelialization occurred similarly at the $7^{\text {th }}$ day postoperative in subgroup $\mathbf{N} 3$ and the control (subgroup N1).

Under TEM examination, in subgroup N3, in the $3^{\text {rd }}$ day postoperative the superficial epithelial layers consisted of flattened lamellate epithelial cells having indented nucleus and vacuolated cytoplasm and the intercellular spaces were dilated. In the $7^{\text {th }}$ day postoperative, TEM examination revealed surface epithelial cells arranged in lamellar manner and their nucleus contained a nucleolus with presence of peri-nuclear space and their cytoplasm contained small electron dens hyaline granules. The presence of vacuoles or empty spaces in between the lamellate layers of keratin was observed. These observations could be explained by (Pastar et al., 2014) ${ }^{[30]}$ who stated that keratinocytes switch from a proliferative state in the basal layer to a differentiated state as they migrate through the granular layer, and finally become the flattened dead cell remnants of the stratum corneum.

Overall, the mentioned results in the non-diabetic group in the current study revealed enhanced wound healing in subgroup $\mathbf{N} 3$ over the control (subgroup N1) although the epithelialization rate was similar in both subgroups. On the other hand, subgroup N2 demonstrated the highest epithelialization rate and the fastest wound healing rate.

Regarding the diabetic group in the present study, H\&E and TEM examination revealed delayed wound healing in subgroup D1 which did not receive any PRP treatment. Complete re-epithelialization with regular rete pegs was not revealed until the $10^{\text {th }}$ day postoperative in subgroup D1. This delay in the rate of healing in diabetic rats as compared with normal control rats came in agreement with (Yu et al., 2014) ${ }^{[40]}$.

The presence of vacuoles in subgroup D1 revealed by TEM examination could be attributed to possible bacterial infection. Cytoplasmic vacuolization is a well-known morphological phenomenon observed in mammalian cells after exposure to bacterial pathogens. Bacterial protein toxins can serve as vacuolization inducers. Vacuolization in cells is considered as an adaptive physiological response which presumably limits any damage (Henics \& Wheatley, 1999; Shubin, Demidyuk, Komissarov, Rafieva, \& Kostrov, 2016) ${ }^{[16,33]}$. Diabetes was postulated to cause this bacterial infection as it was reported to increase the susceptibility to oral infection (Abiko \& Selimovic, 2010) ${ }^{[3]}$.

Very rapid wound healing was obvious in the current study in the diabetic subgroup D2 which was treated with PRP before the wound, when compared with subgroup D1. Complete re-epithelialization with thick edematous layer of keratinized stratified squamous epithelium was revealed in subgroup D2 in the $3^{\text {rd }}$ day postoperative. Regarding, the diabetic subgroup D3 which received PRP treatment after the wound, complete re-epithelialization by thin, lightly stained keratinized stratified squamous epithelium with regular rete pegs was observed in the $7^{\text {th }}$ day postoperative.

Collectively, all the observations of the current study displayed the most accelerated wound healing in the subgroups treated with PRP before the wound, whether non-diabetic or diabetic, which occurred very early at the $3^{\text {rd }}$ day postoperative in both cases. While complete wound healing was revealed at the $7^{\text {th }}$ day postoperative in both the non-diabetic and diabetic subgroups treated with PRP after the wound, which was like the non-diabetic control subgroup. Whilst, the diabetic non-treated subgroup was the last to show wound healing which took place at the $10^{\text {th }}$ day postoperative. 


\section{CONCLUSION}

It was concluded that PRP could be applied before wounding occurred, to prevent impaired wound healing in diabetic oral mucosal wounds and to enhance wound healing in non-diabetic wounds. It was also concluded that PRP could be used after wounding to accelerate wound healing in diabetic and non-diabetic oral mucosal wounds.

\section{REFERENCES}

1. A Hamid, M., Yusof, A., \& Ali, M. (2014). PlateletRich Plasma (PRP) for Acute Muscle Injury: A Systematic Review. PLoS ONE, 9, e90538. doi:10.1371/journal. pone.0090538

2. Abd-Elmotelb, M. A. (2018). Morphometric, Histological and Immunohistochemical Study of Tongue Epithelium in Diabetic Rats. Life Science Journal, 15(11), 1-6. doi:10.7537/marslsj151118.01

3. Abiko, Y., \& Selimovic, D. (2010). The mechanism of protracted wound healing on oral mucosa in diabetes. Review. BOSNIAN JOURNAL OF BASIC MEDICAL SCIENCES, 10(3), 188-191.

4. Bennett, N.T., \& Schultz, G. S. (1993). Growth factors and wound healing: Part II. Role in normal and chronic wound healing. The American Journal of Surgery, 166(1), 74-81. doi:https://doi.org/10.1016/S0002-9610(05)80589-6

5. Blair, P., \& Flaumenhaft, R. (2009). Platelet $\alpha$-granules: Basic biology and clinical correlates. Blood reviews, 23(4), 177-189. doi:10.1016/j.blre.2009.04.001

6. Bozzola, J. J., \& Russell, L. D. (1999). Electron Microscopy: Principles and Techniques for Biologists. (Second ed.). Boston: Jones and Bartlett Publishers International.

7. Chicharro-Alcántara, D., Rubio-Zaragoza, M., DamiáGiménez, E., Carrillo-Poveda, J. M., Cuervo-Serrato, B., Peláez-Gorrea, P., \& Sopena-Juncosa, J. J. (2018). Platelet rich plasma: New insights for cutaneous wound healing management. Journal of Functional Biomaterials, 9(1). doi:10.3390/jfb9010010

8. Chicharro, D., Carrillo, J. M., Rubio, M., Cugat, R., Cuervo, B., Guil, S., . . . Sopena, J. (2018). Combined plasma rich in growth factors and adipose-derived mesenchymal stem cells promotes the cutaneous wound healing in rabbits. BMC Veterinary Research, 14(1). doi:10.1186/ s12917-018-1577-y
9. Choudhary, P., \& Choudhary, O. P. (2018). Uses of Transmission Electron Microscope in Microscopy and its Advantages and Disadvantages. International Journal of Current Microbiology and Applied Sciences, 7(5), 743-747.

10. Dhillon, R. S., Schwarz, E. M., \& Maloney, M. D. (2012). Platelet-rich plasma therapy - future or trend? Arthritis Research \& Therapy, 14(4), 219-219. doi:10.1186/ar3914

11. Dhurat, R., \& Sukesh, M. S. (2014). Principles and methods of preparation of platelet-rich plasma: A review and author's perspective. J Cutan Aesthet Surg, 7, 189-197.

12. Drury, R. A., \& Wallington, E. A. (1980). Carleton's Histological Techniques (5th ed.). New York: Oxford University Press.

13. Gazaerly, H. E., Elbardisey, D. M., Eltokhy, H. M., \& Teaamab, D. (2013). Effect of Transforming Growth Factor Beta 1 on Wound Healing in Induced Diabetic Rats. International Journal of Health Sciences, 7(2), 160-172.

14. Gurtner, G. C., Werner, S., Barrandon, Y., \& Longaker, M. T. (2008). Wound repair and regeneration. Nature, 453(7193), 314-321. doi:10.1038/nature07039

15. Häkkinen, L., Larjava, H., \& Koivisto, L. (2012). Granulation tissue formation and remodeling. Endodontic Topics, 24(1), 94-129. doi:10.1111/etp.12008

16. Henics, T., \& Wheatley, D. N. (1999). Cytoplasmic vacuolation, adaptation and cell death: A view on new perspectives and features. Biology of the Cell, 91(7), 485-498. doi:10.1016/S0248-4900(00)88205-2

17. Italiano, J. E., Jr., Richardson, J. L., Patel-Hett, S., Battinelli, E., Zaslavsky, A., Short, S., Klement, G. L. (2008). Angiogenesis is regulated by a novel mechanism: pro- and antiangiogenic proteins are organized into separate platelet alpha granules and differentially released. Blood, 111(3), 1227-1233. doi:10.1182/blood-2007-09-113837

18. Jee, C.-H., Eom, N.-Y., Jang, H.-M., Jung, H.-W., Choi, E.S., Won, J.-H., . . Jung, D.-I. (2016). Effect of autologous platelet-rich plasma application on cutaneous wound healing in dogs. Journal of veterinary science, 17(1), 79-87. doi:10.4142/jvs.2016.17.1.79

19. Kramer, M. E., \& Keaney, T. C. (2018). Systematic review of platelet-rich plasma (PRP) preparation and composition for the treatment of androgenetic alopecia. Journal of Cosmetic Dermatology, 17(5), 666-671. doi:10.1111/ jocd.12679

20. Lamster, I. B. (2014). Non-periodontal oral complications of diabetes mellitus. Diabetes Mellitus and Oral Health, 157-190. doi:doi:10.1002/9781118887837.ch8 
21. Law, J. X., Chowdhury, S. R., Saim, A. B., \& Idrus, R. B. H. (2017). Platelet-rich plasma with keratinocytes and fibroblasts enhance healing of full-thickness wounds. Journal of Tissue Viability, 26(3), 208-215. doi:http://dx.doi. org/10.1016/j.jtv.2017.05.003

22. López-Jornet, P., Camacho-Alonso, F., Molina-Miñano, F., \& Vicente-Ortega, V. (2009). Effects of plasma rich in growth factors on wound healing of the tongue. Experimental study in rabbits. Medicina Oral, Patologia Oral y Cirugia Bucal, 14(9), e425-e428.

23. Maciel, F. B., DeRossi, R., Módolo, T. J. C., Pagliosa, R. C., Leal, C. R. J., \& Delben, A. A. S. T. (2012). Scanning electron microscopy and microbiological evaluation of equine burn wound repair after platelet-rich plasma gel treatment. Burns, 38(7), 1058-1065. doi:http://dx.doi. org/10.1016/j.burns.2012.02.029

24. Mehmet Esat Duymus, Selim Temel, Hilal Ozer, Mustafa Kemal Urhan, Ferudun Kaya, Fatih Aslan, Kismet, K. (2016). Comparison of the Effects of Platelet rich Plasma Prepared in Various Forms on the Healing of Dermal Wounds in Rats. Wounds, 28(3), 99-108.

25. Middleton, K. K., Barro, V., Muller, B., Terada, S., \& Fu, F. H. (2012). Evaluation of the Effects of Platelet-Rich Plasma (PRP) Therapy Involved in the Healing of SportsRelated Soft Tissue Injuries. The Iowa Orthopaedic Journal, 32, 150-163.

26. Molina-Miñano, F., López-Jornet, P., Camacho-Alonso, F., \& Vicente-Ortega, V. (2009). The use of plasma rich in growth factors on wound healing in the skin: Experimental study in rabbits. International Wound Journal, 6(2), 145148. doi:10.1111/j.1742-481X.2009.00592.x

27. Nanci, A. (2018). Oral Mucosa Ten Cate's Oral Histology: Development, Structure, and Function (9th ed., pp. 589661). St. Louis, Missouri: ElSevier.

28. O’Connell, B., Wragg, N. M., \& Wilson, S. L. (2019). The use of PRP injections in the management of knee osteoarthritis. Cell and Tissue Research, 376(2), 143-152. doi:10.1007/s00441-019-02996-x

29. Ostvar, O., Shadvar, S., Yahaghi, E., Azma, K., Fayyaz, A. F., Ahmadi, K., \& Nowrouzian, I. (2015). Effect of plateletrich plasma on the healing of cutaneous defects exposed to acute to chronic wounds: a clinico-histopathologic study in rabbits. Diagnostic Pathology, 10(85), 1-6.

30. Pastar, I., Stojadinovic, O., Yin, N. C., Ramirez, H., Nusbaum, A. G., Sawaya, A., Tomic-Canic, M. (2014). Epithe- lialization in Wound Healing: A Comprehensive Review. Advances in wound care, 3(7), 445-464. doi:10.1089/ wound.2013.0473

31. Rabo, A., \& Mohamed, R. A. (2018). Comparative Study of the Effect of Allium Sativum (Garlic), Allium Cepa (Onion) \& Insulin on the Lingual Papillae of Streptozotocin Induced Diabetic Albino Rats. (PhD), Ain Shams University, Faculty of Dentistry.

32. Rashed, F. M., GabAllah, O. M., AbuAli, S. Y., \& Shredah, M. T. (2019). The Effect of Using Bone Marrow Mesenchymal Stem Cells Versus Platelet Rich Plasma on the Healing of Induced Oral Ulcer in Albino Rats. International Journal of Stem Cells, 12(1), 95-106. doi:10.15283/ ijsc 18074

33. Shubin, A. V., Demidyuk, I. V., Komissarov, A. A., Rafieva, L. M., \& Kostrov, S. V. (2016). Cytoplasmic vacuolization in cell death and survival. Oncotarget, 7(34), 5586355889. doi:10.18632/oncotarget.10150

34. Singer, A. J., \& Clark, R. A. F. (1999). Cutaneous Wound Healing. New England Journal of Medicine, 341(10), 738746. doi:10.1056/NEJM199909023411006

35. Tandon, P. N., Mahajan, R. C., Anand, N., Basu, S. K., Ganguly, N. K., \& Kamboj, V. P. (2000). Guidelines for care and use of animals in scientific research. New Delhi: Indian National Science Academy.

36. Tian, J., Cheng, L. H. H., Cui, X., Lei, X. X., Tang, J. B., \& Cheng, B. (2019). Application of standardized platelet-rich plasma in elderly patients with complex wounds. Wound Repair and Regeneration, 27(3), 268-276. doi:10.1111/ wrr. 12702

37. Venter, N. G., Marques, R. G., Santos, J. S. d., \& MonteAlto-Costa, A. (2016). Use of platelet-rich plasma in deep second- and third-degree burns. Burns, 42(4), 807-814. doi:http://dx.doi.org/10.1016/j.burns.2016.01.002

38. Williams, D. B., \& Carter, C. B. (2009). The Transmission Electron Microscope In A. McNamara (Ed.), Transmission Electron Microscopy- A Textbook for Materials Science (pp. 3-22). USA: Springer.

39. Winning, T. A., \& Townsend, G. C. (2000). Oral mucosal embryology and histology. Clinics in Dermatology, 18(5), 499-511. doi:https://doi.org/10.1016/S0738081X(00)00140-1

40. Yu, H., Yuan, L., Xu, M., Zhang, Z., \& Duan, H. (2014). Sphingosine kinase 1 improves cutaneous wound healing in diabetic rats. Injury, 45. doi:10.1016/j.injury.2014.03.003 